\title{
A Population Based Survey on the Association Between Tobacco Smoking and Cardiovascular Risk Using WHO Risk Prediction Algorithm Among a Rural Population in Mangalore, Karnataka
}

\section{Shiny Chrism Queen Nesan $\mathbf{G}^{1}$, Rashmi Kundapur ${ }^{2}$, Rakesh Maiya $\mathbf{G}^{\mathbf{3}}$}

${ }^{1}$ Assistant Professor, Department of Community Medicine, Saveetha Medical College, Thandalam, Chennai, Tamil Nadu; ${ }^{2}$ Additional Professor, All India Institute of Medical Sciences, Bibinagar, Hyderabad, Telangana State; ${ }^{3}$ Assistant Professor, Department of Community Medicine, Saveetha Medical College, Thandalam, Chennai, Tamil Nadu

\begin{tabular}{|c|c|c|c|c|c|c|c|c|}
\hline Abstract & Introduction & Methodology & Results & Conclusion & References & Citation & \multicolumn{2}{|c|}{ Tables / Figures } \\
\hline \multicolumn{9}{|c|}{ Corresponding Author } \\
\hline \multicolumn{8}{|c|}{$\begin{array}{l}\text { Dr Rakesh Maiya G, Department of Community Medicine, Saveetha Medical College \& Hospital, } \\
\text { Chennai, Tamil Nadu } \\
\text { E Mail ID: rakeshmaiyag@gmail.com }\end{array}$} & 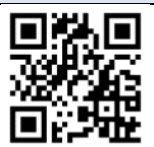 \\
\hline
\end{tabular}

\section{Citation}

Nesan SCQG, Kundapur R, Maiya RG. A Population Based Survey on the Association Between Tobacco Smoking and Cardiovascular Risk Using WHO Risk Prediction Algorithm Among a Rural Population in Mangalore, Karnataka. Indian J Comm Health. 2020;32(4):653-658. https://doi.org/10.47203/IJCH.2020.v32i04.008

Source of Funding: Nil Conflict of Interest: None declared

\section{Article Cycle}

Received: 25/08/2020; Revision: 15/10/2020; Accepted: 05/11/2020; Published: 31/12/2020

This work is licensed under a Creative Commons Attribution 4.0 International License.

\section{Abstract}

Background: Higher proportion of people die in India due to Cardiovascular diseases. Smoking causes about $10 \%$ of all CVD and 6 million people die from tobacco smoking every year through CVD, cancer and other causes. Aims \& Objectives: To determine the risk of developing cardiovascular events (fatal and non-fatal MI or Stroke) among the individuals above 40 years of age in next 10 years and to assess its magnitude of association with the smoking patterns among the study subjects. Methodology: A cross sectional study was conducted at Rural Mangalore among 230 residents above 40 years who were selected by simple random sampling. Pretested \& pre validated proforma for sociodemographic details, WHO/ISH cardiovascular risk prediction algorithm and GATS (Global Adult Tobacco Survey) Questionnaire was used. Statistics used: Chi square test and Multiple logistic regression was used. Data was analysed using SPSS version 22 software. Results: Out of 230 participants, 64\% were males and $36 \%$ were females. WHO colour coding shows that $64.8 \%$ had low risk, $25.7 \%$ had moderate risk and $9.5 \%$ had high risk of getting CVD. 58.3\% consumed chewable tobacco. Current smokeless tobacco users had moderate risk of CVD and Current smokers, current and past smokeless tobacco users had high risk of getting CVD independently. Conclusion: An increased risk of nonfatal myocardial infarctions among tobacco chewers was relatively lesser than for smokers and the highest increase in risk of acute myocardial infarction was in smokers who also chewed tobacco.

\section{Keywords}

CVD, Chewable Tobacco, GATS, Risk level, Tobacco Forms

\section{Introduction}

In India, NCDs accounts for about $53 \%$ of all deaths of which cardiovascular diseases accounts for $24 \%$ of deaths and it was observed that currently Indians experience CVD deaths at least a decade earlier than their counterparts in well developed countries.(1)A higher proportion of people die in India and other south Asian countries compared to other developed countries due to CVD which emphasizes the effect on 
the family economics. (2)A conservative estimate indicates that there could be 30 million CVD patients in India of which 14 million are in urban and 16 million are in rural areas.(3) If the current trend continues, by the year 2020 the burden of cardiovascular disease in India will surpass other regions of the world. The individual's behavioral risk factors play a major role on their health outcome and these behavioral determinants can be modified depending on the individuals and their personal habits. Health correlated behaviors such as tobacco, alcohol, physical activities, diet plays a major role on morbidity and mortality related to CVD.(4) According to a study on regional variations of risk factors on CVD in India, it is observed that the most prevalent risk factor among urban population is hypertension, whereas among rural population it is smoking.(5) About a billion people are current smokers in the world and the numbers taking up tobacco smoking anew was highest among men from lower middle income countries. Smoking is estimated to cause about $10 \%$ of all CVD and close to 6 million people die from tobacco smoking every year through CVD, cancer and other causes.(3)

\section{Aims \& Objectives}

1. To determine the risk of developing cardiovascular events (fatal and non-fatal MI or Stroke) among the individuals above 40 years of age in next 10 years

2. To assess the magnitude of association between cardiovascular event with the smoking patterns among the study subjects.

\section{Material \& Methods}

A cross sectional community health survey was conducted in Bengre, a rural field practice area of Mangalore, Karnataka. This study was conducted for four months among the individuals above the age of 40 years residing in this village irrespective of their gender. A previous study conducted in Puducherry, reported that $17 \%$ of subjects had moderate to high risk of developing CVD in next 10 years. (6) Thus, with $5 \%$ allowable error and using formula $4 \mathrm{pq} / \mathrm{d}(2)$ the sample size derived as 225 . Totally, 230 study participants were involved in the study using simple random sampling method to select the households and the person who is eldest in the household was considered for the study. A pre - validated, pre tested and semi structured questionnaire was prepared to observe socio demographic characteristics, WHO/ISH cardiovascular risk prediction algorithm for South East Asian region Annexure 4(3) was used to predict 10 years' risk of developing fatal and non-fatal MI or stroke and GATS (Global Adult Tobacco Survey) (7) Questionnaire to assess tobacco consumption patterns. All people above 40 years and permanent residents of Bengre who were willing to participate in the study were included and those who are diagnosed with $\mathrm{Ml}$ or stroke, mentally unstable and moribund subjects were excluded from the study. This study had obtained the ethical clearance approval from the institutional ethical committee of K.S Hegde Medical Academy, Mangalore, Karnataka. Written informed consent was obtained from all study participants before eliciting the desired information. The collected information was summarized by using descriptive statistics such as frequencies and percentage. Chi square test (Inferential Statistics) and Likelihood ratio was used for univariate analysis. The multivariate logistic regression technique was used to identify the independent risk factors for cardiovascular disease. $\mathrm{p}$ value $<0.05$ was considered significant. Data management and analysis was done by using Microsoft excel and SPSS version 22.

\section{Results}

Among 230 participants, 147 (64\%) were males and $83(36 \%)$ were females. Majority of the males were in the age group of $40-50$ years $(26.1 \%)$ and majority of females were in the age group of $51-60$ years $(15.7 \%)$. Most of the study participants belonged to the socio-economic status of Lower middle class (43\%), as per Modified B G Prasad socio economic classification scale, proposed in 2018. It was observed that most of the males in our study population were unskilled workers (12.2\%) and most of the females were housewives (17.4\%), of which majority of the males had their works related to fishing which included skilled, semi-skilled and unskilled works. Among females 5.7\% were unskilled workers which mainly involved bidi rolling in their homes itself. It was seen that $\mathbf{8 7 . 4 \%}$ were married during the time of data collection and only 2 male participants were unmarried. $33.5 \%$ of the study participants taken were Hypertensives (20.6\% were males and $10.9 \%$ were females), $30.4 \%$ of them had both Diabetes Mellitus and Hypertension (20.4\% males and $10 \%$ females) and only $1.7 \%$ had Diabetes Mellitus (0.9\% males and $0.9 \%$ females). $27.4 \%$ of study participants had a strong family history of 
Hypertension and $24.8 \%$ of both Diabetes Mellitus and Hypertension.

[Figure 1] shows the Prevalence of WHO Risks categories prevalent among the study participants, it was observed that $64.8 \%$ had $<10 \%$ risk of which, $40.4 \%$ were males and $24.3 \%$ were females. $5.2 \%$ had $>40 \%$ risk which is the highest risk score of which $3.9 \%$ were males and $1.3 \%$ were females. According WHO color coding it shows that $64.8 \%$ had low risk, $25.7 \%$ had moderate risk and $9.5 \%$ had high risk of getting CVD in next 10 years. It is remarkable that $5.2 \%$ of them had the highest risk $(>40 \%)$ of getting CVD.

Among 230 participants, 108 (47\%) of them were current tobacco users $(32.6 \%$ males and $14.3 \%$ females). $21.3 \%$ smoked tobacco daily and $22.6 \%$ used smokeless tobacco daily. [Table 1] shows widely used tobacco products among the study participants and it was noted that among current tobacco consumers majority of $58.3 \%$ used chewable form of tobacco. These values are interrelated i.e. the participants used more than one product of tobacco are shown in the table. (Figure 2) shows the distribution of frequency of different forms of tobacco used per day per week. Majority of $84.3 \%$ participants used hand rolled cigarettes/bidis for $6-$ 10 times per day per week, followed by $52.4 \%$ participants used chewable tobacco for $1-5$ times per day per week and $50 \%$ of participants used manufactured cigarettes for 6 - 10 times per day per week. The most frequently consumed form of tobacco, more than 10 times per day per week among our study participants was chewable form of tobacco (22.2\%), followed by manufactured cigarettes (12.5\%) and hand rolled cigarettes / bidis (9.8\%).

Association between the tobacco consumption pattern and CVD risk prediction score was seen and it is shown in [Table 2]. It is observed that $8.2 \%$ of daily smokers had $>40 \%$ risk level of getting CVD than $4 \%$ of participants who had never smoked. On comparing with $<10 \%$ risk level of getting CVD it was seen $67.8 \%$ who had never smoked at all had higher risk than $55.1 \%$ of daily smokers. These findings were statistically significant with $p$ value 0.001 . It was seen that $11.5 \%$ of past smokers had $>40 \%$ risk level of getting CVD than the participants who were not past smokers $(3.4 \%)$ which was statistically significant with $p$ value $<0.001$. 9.6\% of current smokeless tobacco users had $>40 \%$ risk level of CVD than $3.9 \%$ of participants who never used it. It was also observed that $70.2 \%$ of participants who never used smokeless tobacco had $<10 \%$ risk level of getting CVD than $46.2 \%$ of daily smokeless tobacco users. The findings were significant with $p$ value 0.019 . It was also noticed that $9.1 \%$ of past smokeless tobacco users had $>40 \%$ risk level of getting CVD than $4 \%$ of participants who did not use smokeless tobacco in the past, which was statistically significant with $p$ value 0.023 . On observing the frequency of tobacco usage per day per week it was seen that $63.2 \%$ of participants who used $>10$ times/day/week had $<10 \%$ of risk level of getting CVD than $47.5 \%$ of them who used $1-5$ times/day/week. But only $5.3 \%$ of $>10$ times/day per/week had $>40 \%$ risk level of getting CVD than $7.5 \%$ who used 1- 5 times/day/week. This finding was statistically significant with $p$ value 0.001 .

Finally, considering all the statistically significant factors of association, multi nominal regression was done to find the independent risk factors without the confounding factors affecting the results. In [Table 3], considering $<10 \%$ as low risk level and reference, $10-29.9 \%$ as moderate risk level and $>30 \%$ as highrisk level, the multiple logistic regression was done. It was observed that current smokeless tobacco users had moderate risk level of getting CVD $(p=<0.001 / A O R=1.603 / \mathrm{Cl}(0.827-9.085))$ which was highly significant and current smokers $(p=0.013 / A O R=6.265 / C l \quad(1.473-26.649))$, current smokeless tobacco users $(p=<0.001 / A O R=1.933 / \mathrm{Cl}(1.852-9.687)) \quad$ and past smokeless tobacco users $(p=<0.001 / A O R=15.624 / C l \quad(3.648-66.915))$ had high risk level of CVD.

\section{Discussion}

According to our study $47 \%$ of the participants consumed tobacco either in the smoking form or in smokeless form, of which $32.2 \%$ were males and $14.8 \%$ were females. The NFHS-3(8) reports that the proportion of male respondents consuming any form of tobacco is $49.9 \%$ in urban men and $61.1 \%$ in rural men and the prevalence of smoking was higher among rural population as compared to urban regions. In our study the prevalence of current tobacco users was $47 \%$ which is lesser than the NFHS-3 reports. In a study done by Gupta et al (9) in North Indian communities it was observed that the usage of Bidis was very high among men (44.6\%) and women (11\%) which is like the results in our study. It 
was also observed that the usage of manufactured cigarettes was much lesser when compared to the usage of bidis which was also like our findings. Since the manufactured cigarettes are expensive and the people in rural setting will not be able to afford it on daily usage it was obvious that bidis were used more than the cigarettes. These findings were also observed in other researches done by Jindal et al.(10) and Chaudhary et al.(11) in rural as well as urban settings.

The results of our study agree with the report given by GATS 2009 - 10(12) that males commonly use smoking form of tobacco whereas females mostly use chewable or smokeless form of tobacco and the most commonly used form of tobacco among rural population is bidi/hand rolled cigarettes. In a study done in Chennai (13) it was observed that the tobacco usage among males were higher than the females which was like our results. The use of smokeless tobacco by women in our study supports the finding reported by Giovino et al (14) that use of smokeless tobacco among women is prevalent in Asian counties like India, China and Bangladesh. It was observed in our study that current daily tobacco users had high risk ( $>40 \%$ ) of getting CVD than persons who has never smoked at all. The INTERHEART study (15) conducted in 52 countries also reported that current smoking was associated with a greater risk of non-fatal myocardial infarction compared with never smoking. It was a remarkable finding in our study that the association between the smoking and smokeless tobacco and its frequency and occurrence of cardiovascular event was statistically significant. The tobacco usage was found to be independent risk factor for cardiovascular disease after the multi-nominal regression model as well. The very similar findings were reported by Rohit and Trivedi (16) in their case control study that smokers and smokeless tobacco users were more among cases than controls and this finding was statistically significant to cause cardiovascular event. The study also reported that most commonly used form of tobacco by smokers were bidis and among smokeless tobacco users it was chewing tobacco which was a similar finding with our study. It was observed in our study that daily smokers have $8.2 \%$ of $>40 \%$ of getting CVD, whereas smokeless tobacco users have $9.6 \%$ of risk. This finding shows that smokeless tobacco users are in increased risk for uneventful cardiovascular event than smokers.

\section{Conclusion}

There was an increased risk of non-fatal myocardial infarctions among tobacco chewers, though relatively lesser than for smokers and the highest increase in risk of acute myocardial infarction was in smokers who also chewed tobacco. The females used more of chewable form of tobacco whereas the males smoked high number of bidis.

\section{Recommendation}

As smoking is considered as single largest cause for death, disability, preventable illness and unnecessary health expenditure in India, more steps must be taken by the government to create awareness on the fatal effects of smoking and to prevent the rapid spread of Non-Communicable diseases such as Cardiovascular diseases and Lung / Oral cancers related to smoking.

\section{Limitation of the study}

Limited sample size might have caused discrepancies in the results. The results from our study cannot be generalized to the populations dissimilar to ours. As it was a cross sectional study, we did not follow up the participants after revealing their risk prediction for CVD and we were not able to assure behavior modification among the participants as well.

\section{Relevance of the study}

Even though this is one of the every other study that infers the ill effects of smoking, more studies like this must be conducted so that the results can be used to emphasize to the Government on the total ban on all forms of tobacco products all over India and to also focus on the strict implementation of the same as Tobacco consumption is one of the known risk factor for many respiratory infection and it increases the severity of related disease.

\section{Authors Contribution}

All authors have contributed equally.

\section{References}

1. World Health Organization. NCD Country Profiles [Internet]. WHO Available from: http://www.who.int/nmh/countries ind en.pdf?ua=1. (Accessed on 2020 Dec 18)

2. Valentin, and Bridget B. "Promoting Cardiovascular Health in the Developing World A Critical Challenge to Achieve Global Health." National Academies Press, 2010, doi: $10.17226 / 12815$

3. Cardiovascular diseases (CVDs) [Internet]. World Health Organization. World Health Organization; [cited 2020 Dec 06]. Available from: http://www.who.int/en/news-room/factsheets/detail/cardiovascular-diseases-(cvds).

4. Barolia RI, Clark AM, Higginbottom GM. Protocol for a qualitative study on promoting dietary change and positive 
food choices for poor people with low income who experience cardiovascular disease in Pakistan. BMJ Open. 2013 4;3(12):e004176. doi: 10.1136/bmjopen-2013-004176. PMID: 24309173; PMCID: PMC3855597.[PubMed].

5. Regional variations in cardiovascular risk factors in India: India heart watch. - PubMed - NCBI [Internet]. [cited 2020 Dec 22]. Available from: http://www.ncbi.nlm.nih.gov/pubmed/22558490

6. WHO | Preventing chronic diseases: a vital investment [Internet]. [cited 2020 Dec 06]. Available from: http://www.who.int/chp/chronic disease report/en/

7. GATS Atlas | Global Adult Tobacco Survey [Internet]. Gatsatlas.org. 2010 [cited 31 Dec 2020]. Available from: http://gatsatlas.org/

8. International Institute for Population Sciences (IIPS) and Macro International. 2007. National Family Health Survey (NFHS-3). 2005-06: India: Volume I. Mumbai: IIPS.

9. Gupta V, Yadav K, Anand K. Patterns of tobacco use across rural, urban, and urban-slum populations in a north Indian community. Indian J Community Med. 2010;35(2):245-51. doi: 10.4103/0970-0218.66877. PMID: 20922100; PMCID: PMC2940179.[PubMed].

10. Jindal SK, Aggarwal AN, Chaudhry K, Chhabra SK, D'Souza GA, Gupta D, Katiyar SK, Kumar R, Shah B, Vijayan VK; Asthma Epidemiology Study Group. Tobacco smoking in India: prevalence, quit-rates and respiratory morbidity. Indian J Chest Dis Allied Sci. 2006;48(1):37-42. PMID: 16482950.[PubMed].

11. Chaudhry K, Prabhakar AK, Prabhakaran PS, Prasad A, Singh K, Singh A. Prevalence of tobacco use in Karnataka and Uttar Pradesh in India. Final report of the study by the Indian Council of Medical Research and the WHO South East Asian Regional Office, New Delhi; 2001. Cross referenced from: Reddy KS,
Gupta PC, editors. Report on Tobacco Control in India. Ministry of Health and Family Welfare. New Delhi: Government of India; 2004.

12. Ministry of Health and Family Welfare, Government of India. Global Adult Tobacco Survey: India Report 2009- 10. New Delhi, India, $2010 . \quad$ Available from: http://mohfw.nic.in/WriteReadData/l892s/1455618937GATS \%20India.pdf [Accessed on 06 Aug 2020].

13. Chockalingam K, Vedhachalam C, Rangasamy S, Sekar G, Adinarayanan S, Swaminathan S, Menon PA. Prevalence of tobacco use in urban, semi urban and rural areas in and around Chennai City, India. PLoS One. 2013 1;8(10):e76005. doi: 10.1371/journal.pone.0076005. PMID: 24098418; PMCID: PMC3788037.[PubMed].

14. Giovino GA, Mirza SA, Samet JM, Gupta PC, Jarvis MJ, Bhala N, Peto R, Zatonski W, Hsia J, Morton J, Palipudi KM, Asma S; GATS Collaborative Group. Tobacco use in 3 billion individuals from 16 countries: an analysis of nationally representative crosssectional household surveys. Lancet. 2012 18;380(9842):66879. doi: 10.1016/S0140-6736(12)61085-X. Erratum in: Lancet. 2012 Dec 1;380(9857):1908. Erratum in: Lancet. $2013 \mathrm{Jul}$ 13;382(9887):128. PMID: 22901888. [PubMed].

15. Teo KK, Ounpuu S, Hawken S, Pandey MR, Valentin V, Hunt $D$, Diaz $R$, Rashed W, Freeman $R$, Jiang $L$, Zhang $X$, Yusuf $S$; INTERHEART Study Investigators. Tobacco use and risk of myocardial infarction in 52 countries in the INTERHEART study: a case-control study. Lancet. 2006 19;368(9536):647-58. doi: 10.1016/S0140-6736(06)69249-0. PMID: 16920470.[PubMed].

16. Rohit V R, Atul V T. Smoking, Smokeless Tobacco Consumption \& Coronary Artery Disease - A Case Control Study. National Journal of Community Medicine. 2012;3(2):264 - 268.

\section{Tables}

TABLE 1 DISTRIBUTION OF GENDER-BASED TOBACCO PRODUCTS CURRENTLY USED (N = 108)

\begin{tabular}{|l|c|c|c|}
\multicolumn{1}{|c|}{} & MALES & FEMALES & TOTAL \\
\hline TOBACCO PRODUCTS USED & $\mathbf{N}(\%)$ & $\mathbf{N}(\%)$ & $\mathbf{N}(\%)$ \\
\hline Manufactured cigarettes & $8(7.4 \%)$ & 0 & $8(7.4 \%)$ \\
\hline Hand rolled cigarettes/ Bidis & $46(42.5 \%)$ & $5(4.6 \%)$ & $51(47.2 \%)$ \\
\hline Chewable tobacco & $29(26.8 \%)$ & $34(31.4 \%)$ & $63(58.3 \%)$ \\
\hline
\end{tabular}

TABLE 2 ASSOCIATION OF WHO RISK SCORE WITH TOBACCO USAGE PATTERN ( $\mathbf{N}=230$ )

\begin{tabular}{|c|c|c|c|c|c|c|}
\hline \multirow[t]{2}{*}{ TOBACCO USAGE PATTERN } & \multicolumn{5}{|c|}{ WHO RISK SCORING ${ }^{* *}$ N (\%) } & \multirow[t]{2}{*}{ p Value } \\
\hline & $<10 \%$ & $10-19.9 \%$ & $20-29.9 \%$ & $30-39.9 \%$ & $>40 \%$ & \\
\hline \multicolumn{7}{|c|}{ Current usage of smoking Tobacco } \\
\hline Daily & $27(55.1 \%)$ & $4(8.2 \%)$ & $8(16.3 \%)$ & $6(12.2 \%)$ & $4(8.2 \%)$ & $0.001^{\$}$ \\
\hline Occasionally & 4 (57.1\%) & 0 & $2(28.6 \%)$ & 0 & $1(14.3 \%)$ & \\
\hline Not at all & $118(67.8 \%)$ & $36(20.7 \%)$ & 9 (5.2\%) & $4(2.3 \%)$ & $7(4 \%)$ & \\
\hline \multicolumn{7}{|l|}{ Past usage of smoking Tobacco } \\
\hline Yes & $27(51.9 \%)$ & $5(9.6 \%)$ & $8(15.4 \%)$ & $6(11.5 \%)$ & $6(11.5 \%)$ & $<0.001^{\$}$ \\
\hline No & $122(68.5 \%)$ & $35(19.7 \%)$ & $11(6.2 \%)$ & $4(2.2 \%)$ & $6(3.4 \%)$ & \\
\hline \multicolumn{7}{|c|}{ Current usage of smokeless Tobacco } \\
\hline Daily & $24(46.2 \%)$ & $14(26.9 \%)$ & $7(3.5 \%)$ & $2(3.8 \%)$ & $5(9.6 \%)$ & $0.019^{\$}$ \\
\hline Not at all & $125(70.2 \%)$ & $26(14.6 \%)$ & $12(6.7 \%)$ & $8(4.5 \%)$ & 7(3.9\%) & \\
\hline \multicolumn{7}{|c|}{ Past usage of smokeless Tobacco } \\
\hline Yes & $26(47.3 \%)$ & $15(27.3 \%)$ & $7(12.7 \%)$ & $2(3.6 \%)$ & $5(9.1 \%)$ & $0.023^{\$}$ \\
\hline No & $123(70.3 \%)$ & $25(14.3 \%)$ & $12(6.9 \%)$ & $8(4.6 \%)$ & $7(4 \%)$ & \\
\hline \multicolumn{7}{|c|}{ Frequency of Tobacco usage each day/ week } \\
\hline $1-5$ times & $19(47.5 \%)$ & $8(20 \%)$ & $9(22.5 \%)$ & $1(2.5 \%)$ & $3(7.5 \%)$ & $0.001^{\$}$ \\
\hline $6-10$ times & $33(53.2 \%)$ & $11(17.7 \%)$ & 6(9.7\%) & $6(9.7 \%)$ & $6(9.7 \%)$ & \\
\hline
\end{tabular}




\begin{tabular}{|c|c|c|c|c|c|c|c|}
\hline \multicolumn{8}{|c|}{ INDIAN JOURNAL OF COMMUNITY HEALTH / VOL 32 / ISSUE NO 04 / OCT - DEC 2020} \\
\hline$>10$ times & \multicolumn{2}{|c|}{$12(63.2 \%)$} & 15.8\%) & 2(10.5) & $1(5.3 \%)$ & $1(5.3 \%)$ & \\
\hline \multicolumn{8}{|c|}{$\$$ likelihood ratio, $p<0.05$ is significant $* *$ WHO/ISH Risk prediction algorithm } \\
\hline \multicolumn{8}{|c|}{ TABLE 3 REGRESSION ANALYSIS PARAMETERS WITH WHO/ISH RISK CATEGORIES (N = 230$)$} \\
\hline \multirow[t]{2}{*}{ Parameters } & \multirow[t]{2}{*}{ Low Risk } & \multicolumn{3}{|c|}{ Moderate Risk } & \multicolumn{3}{|c|}{ High Risk } \\
\hline & & AOR & $\mathrm{Cl}$ & p value & AOR & $\mathrm{Cl}$ & $p$ value \\
\hline Current usage of smoking Tobacco & \multirow[t]{3}{*}{$\mathrm{R}$} & \multirow[t]{3}{*}{0.98} & \multirow[t]{3}{*}{$0.082-11.801$} & \multirow{3}{*}{0.99} & & & \\
\hline Yes & & & & & 6.265 & $1.473-26.649$ & 0.013 \\
\hline \multicolumn{4}{|l|}{$\mathrm{No}^{\mathrm{R}}$} & & & & \\
\hline Past usage of smoking Tobacco & \multirow[t]{3}{*}{$\mathrm{R}$} & \multirow[t]{3}{*}{0.101} & \multirow[t]{3}{*}{$0.010-1.042$} & \multirow[t]{3}{*}{0.54} & \multirow[t]{3}{*}{0.193} & \multirow[t]{3}{*}{$0.018-2.045$} & \multirow[t]{3}{*}{0.172} \\
\hline Yes & & & & & & & \\
\hline No $^{R}$ & & & & & & & \\
\hline Current usage of smokeless Tobacco & \multirow[t]{3}{*}{$\mathrm{R}$} & \multirow[t]{3}{*}{1.603} & \multirow[t]{3}{*}{$0.827-9.085$} & \multirow[t]{3}{*}{$<0.001$} & \multirow[t]{3}{*}{1.933} & \multirow[t]{3}{*}{$1.852-9.687$} & \multirow[t]{3}{*}{$<0.001$} \\
\hline Yes & & & & & & & \\
\hline $\mathrm{No}^{\mathrm{R}}$ & & & & & & & \\
\hline Past usage of smokeless Tobacco & \multirow[t]{3}{*}{$\mathrm{R}$} & & & & & & \\
\hline Yes & & 1.783 & $0.843-3.770$ & 0.13 & 15.624 & $3.648-66.915$ & $<0.001$ \\
\hline \multicolumn{7}{|l|}{$\mathrm{No}^{\mathrm{R}}$} & \\
\hline Frequency each day/week (Tobacco) & \multirow[t]{3}{*}{$\mathrm{R}$} & \multirow[t]{3}{*}{1.01} & \multirow[t]{3}{*}{$0.219-4.658$} & \multirow[t]{3}{*}{0.99} & 1.846 & $0.386-8.829$ & 0.443 \\
\hline$>5$ times & & & & & & & \\
\hline $1-5^{R}$ times & & & & & & & \\
\hline$p<0.05$ is significant & & & & & & & \\
\hline
\end{tabular}

\section{Figures}

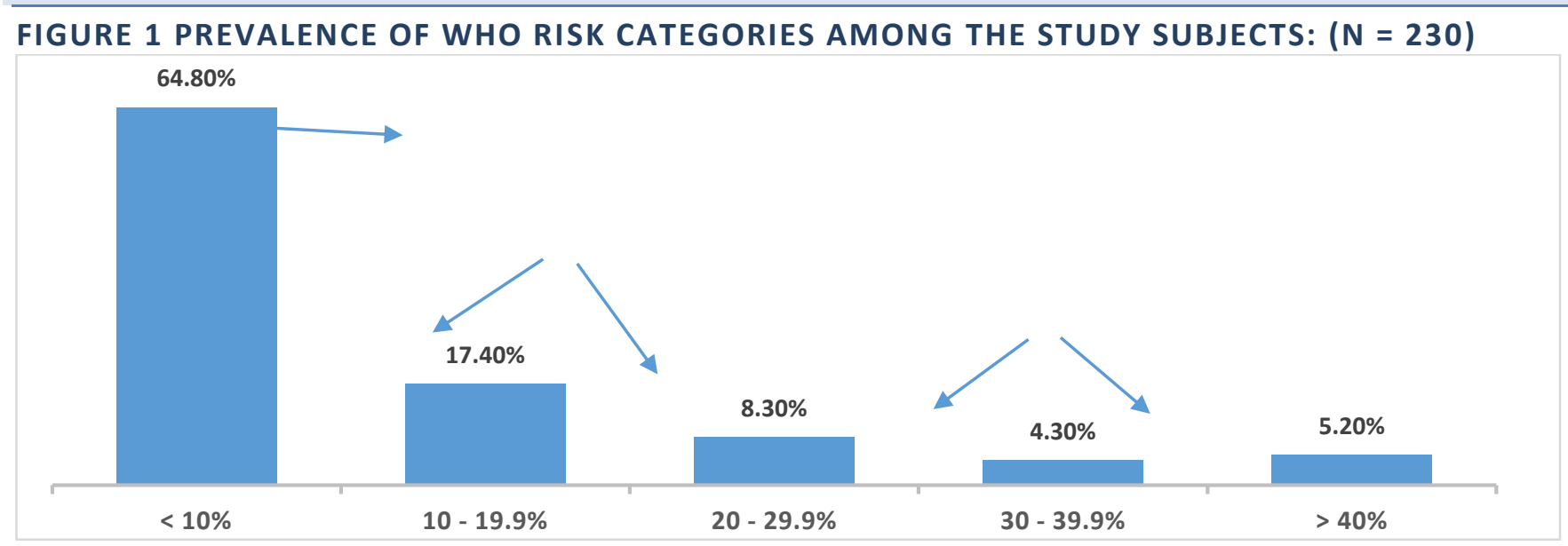

FIGURE 2 DISTRIBUTION OF FREQUENCY OF CONSUMPTION OF DIFFERENT FORMS OF TOBACCO EACH DAY/WEEK AMONG THE STUDY SUBJECTS ( $N=108)$

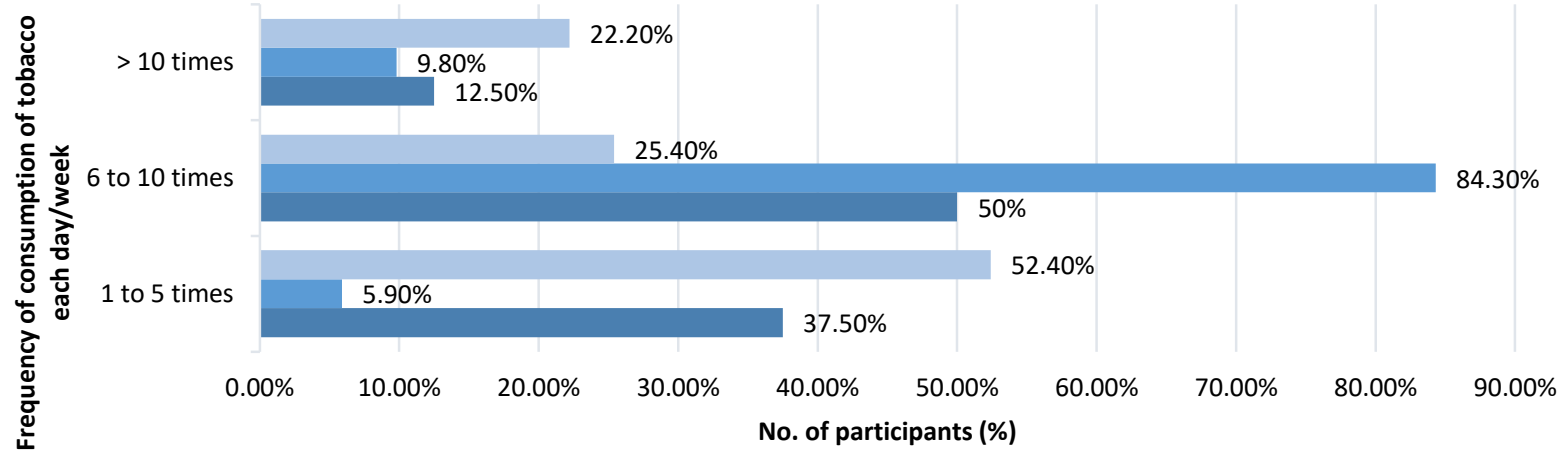

